D.O.I.: $10.3895 / \mathrm{S} 1808-04482009000300001$

\title{
GERAÇÃO DE IDÉIAS PARA INOVAÇÕES: ESTUDOS DE CASOS E NOVAS ABORDAGENS
}

\section{GENERATION OF IDEAS FOR INNOVATION: CASE STUDIES AND NEW APPROACHES}

\author{
José Carlos Barbieri ${ }^{1}$; Antonio Carlos Teixeira Álvares ${ }^{2}$; Jorge Emanuel Reis Cajazeira ${ }^{3}$ \\ ${ }^{1}$ Escola de Administração de Empresas de São Paulo/Fundação Getulio Vargas - FGV/EAESP - \\ São Paulo - Brasil \\ jose.barbieri@fgv.br \\ ${ }^{2}$ Escola de Administração de Empresas de São Paulo/Fundação Getulio Vargas - FGV/EAESP - \\ São Paulo - Brasil \\ teixeira@brasilata.com.br \\ ${ }^{3}$ Suzano Celulose e Papel SA - São Paulo - Brasil \\ cajazeira@susano.com.br
}

\begin{abstract}
Resumo
A geração de idéias é uma questão central da gestão de inovações. Entre as fontes de idéias estão os sistemas de sugestões voltados para estimular e captar idéias dos empregados. Este artigo apresenta uma revisão bibliográfica sobre este tema e os resultados de um estudo realizado em três organizações brasileiras reconhecidas como inovadoras e que possuem sistemas de sugestões que atendem as expectativas para os quais foram criados, segundo seus gestores. O estudo foca a atenção na gestão do sistema, sua adequação ao sistema de gestão global e os resultados alcançados. Este estudo trouxe novas considerações sobre este tema, ensejando novas abordagens teóricas e a proposição de uma nova classificação mais adequada às suas novas atribuições, tais como ampliar a comunicação entre a direção e os empregados, valorizar aspectos intangíveis do ambiente de trabalho e manter um meio inovador interno favorável a todo tipo de inovações incrementais e radicais.
\end{abstract}

Palavras-chave: idéias; invenção; inovação; gestão da inovação; qualidade; sistema de sugestão.

\section{Introdução}

A geração de idéias é uma atividade central dos processos de inovação tanto os que incorporam novidades radicais que criam novos setores econômicos ou alteram a forma de competição entre as empresas, quanto os que trazem pequenas melhorias em produtos e processos conhecidos. Qualquer inovação sempre parte de uma ou mais idéias que se somam às outras geradas em diferentes fases do seu processo de implantação. Este artigo se preocupa com uma fonte 
específica de idéias, os funcionários da organização e os meios para estimular, captar e gerir as suas idéias, denominados genericamente de sistemas de sugestões. Estes sistemas tiveram grande destaque no passado e muitos estudos foram feitos sobre eles, a maioria produzida pelo movimento da qualidade. Os estudos sobre inovação tecnológica deram pouca importância, embora as idéias constituem um dos principais insumos das inovações. A partir dos anos 1990, esses sistemas praticamente desaparecem da literatura administrativa, embora eles continuaram sendo criados por diferentes tipos de organizações, especialmente as grandes empresas manufatureiras. Atualmente esse tema voltou a despertar interesse, agora sobre novas e mais amplas perspectivas.

Inicialmente será apresentada uma revisão teórica sobre as idéias nos processos de inovações e uma analise comparativa das abordagens dominantes para estimular a geração de idéias pelos funcionários. Depois serão apresentados e discutidos os resultados de uma pesquisa baseada em estudos de casos múltiplos em organizações brasileiras reconhecidas como inovadoras e que possuam um sistema de sugestões estruturado. A pesquisa teve como foco a gestão dos sistemas, sua adequação ao modelo de gestão global da empresa e os resultados alcançados. Esse estudo trouxe novas abordagens teóricas sobre este tema, dentre elas, a proposição de uma nova classificação de sistemas de sugestões para dar conta da suas novas atribuições e necessidades de gestão.

\section{Idéias e inovações}

A palavra idéia, nesse trabalho, será usada para indicar um objeto do pensamento, como sua representação ou forma. Uma idéia se expressa mediante opinião, ponto de vista, noção, conhecimento ou qualquer outro meio capaz de representar a concepção mental de algo concreto ou abstrato. A idéia não é apenas representação mental de um objeto existente, mas também uma possibilidade ou a antecipação de algo. De acordo com Dewey (1938), a idéia começa como uma sugestão, mas nem toda sugestão é uma idéia. A sugestão torna-se uma idéia quando examinada com referência a sua possibilidade de resolver uma dada situação (p. 109-10). Para a Japan Human Relations Association, uma sugestão é uma idéia explicitada e comunicada; primeiro tem-se uma idéia que se passa na mente de uma pessoa, que depois a comunica, pela fala ou por escrito, para outros (1997; p.24). Nesse texto os termos idéia e sugestão são usados como sinônimos e entendidos como fontes de invenção e inovação.

Para Rogers (1995; p. 176), a invenção é o processo de desenvolvimento de uma nova idéia. É uma idéia ou sugestão elaborada que se apresenta na forma de planos, fórmulas, modelos, protótipos, descrições e outros meios que permitam registrá-la e comunicá-la. A idéia é o embrião da invenção e entre uma e outra há diferentes trabalhos a serem feitos, constituindo o que se denomina de atividade inventiva, que se caracteriza por ser um trabalho criativo, cujo resultado se 
apresenta nas formas exemplificada acima. Segundo Thomas Alvas Edson, que produziu mais de 1000 invenções patenteadas, o gênio consiste em $\mathbf{1 \%}$ de inspiração e $\mathbf{9 9 \%}$ de transpiração, querendo dizer $1 \%$ de idéias e $99 \%$ de trabalho árduo para transformá-las em invenções. Também se atribui a ele a seguinte frase: não há substituto para o trabalho duro. Essas expressões são atribuídas a esse grande inventor, embora não se encontram em obras escrita pelo autor, mas dita em entrevistas e citadas pelos seus biógrafos. Edson queria com isso dizer que o desenvolvimento de uma idéia requer múltiplas atividades, como pesquisas bibliográficas em documentos técnicos científicos, delineamento e realização de experimentos em diferentes situações, registros de dados, análises, comparações, revisões, reformulações e muitas outras até encontrar aquilo que a idéia antecipara como uma possibilidade.

Inovação é a invenção efetivamente incorporada aos sistemas produtivos. Roberts (1997, pg. 581) considera que a inovação é a invenção e sua exploração com êxito: a invenção envolvendo todos os esforços para criar novas idéias e elaborá-las de um modo que possam ter utilidade práticas; a exploração, todo os estágios de desenvolvimento comercial, aplicação e transferência. Para Van de Ven et al. (2000, pg. 32) é a introdução de uma nova idéia e o processo de inovação refere-se à seqüência temporal de eventos pela qual pessoas se interagem para desenvolver e implementar suas idéias inovadoras num contexto institucional. Gundling (2000. 247, pg. 23) destaca os resultados esperados das inovações, definindo-as como novas idéias mais as ações ou implementações que resultem em melhorias, ganhos ou lucros para a empresa.

Em outras palavras, não há inovação que não teve em sua origem uma idéia, pois como asseveram Freeman e Soete (1997; pg. 202), a inovação é um processo que começa nas mentes de pessoas imaginativas. Por isso, os modelos de inovação sempre fazem referência à geração de idéias como uma fase do processo de inovação. Por exemplo, no modelo descrito por Rothwell (1992; p.222-3) as idéias decorrem de necessidades de mercado ou de oportunidades tecnológicas identificadas e dão origem às atividades de Pesquisa e Desenvolvimento, design, desenvolvimento de protótipos, manufatura, marketing até alcançar o mercado. No modelo do funil de Clark e Wheelwright (1993; p. 293), o processo de inovações começa com a geração de idéias que serão selecionadas conforme os objetivos da empresa e seus condicionantes internos e externos. A boca do funil representa o fato de que muitas idéias devem ser geradas e quanto mais idéias melhor, pois apenas algumas poucas serão implementadas.

É conhecido o fato de nem todas as idéias são aproveitadas. Muitos estudos apontaram esse fato, como o conhecido pelo artigo de Booz, Allen e Hamilton de 1968, na qual apresenta uma curva do decaimento das idéias resultante da rejeição progressiva de idéias e projetos pelos estágios de um processo de desenvolvimento de novos produtos. Stevens e Burley (1997) mostram que para muitas indústrias são necessárias 3.000 idéias em estado inicial (raw ideas) para se obter um novo 
produto que alcance sucesso comercial significativo, que o autor denomina de jóia da coroa. Esse número é menor no caso de inovações que representam extensões da linha de produtos. Esses autores representam o processo de inovação como uma curva de sucesso na qual o número de idéias vai declinando à medida que avançam para os estágios mais próximos do lançamento comercial (p. 17). o que leva a esse declínio é fato de a idéia em seu estado inicial precisa ser aperfeiçoada em conformidade com inúmeros condicionantes organizacionais, tecnológicos e mercadológicos. Por isso, gerar idéias em quantidade torna-se importante para as empresas em que a inovação constante faça parte da sua estratégia competitiva.

\subsection{Fontes de Idéias}

Independentemente do grau de novidade da inovação, se radical ou incremental, as idéias surgem em função de dois motivos básicos: problemas, necessidades e oportunidades relacionadas com a produção e comercialização de bens e serviços; e oportunidades vislumbradas com a ampliação dos conhecimentos que ocorrem tanto na própria empresa quanto no seu ambiente geral. As idéias sobre produtos, processos e negócios, novos ou modificados, provêm das mais diversas fontes, por exemplo, vendedores, consumidores, fornecedores, administradores e funcionários, consultores, pessoal de Pesqusa e Desenvolvimento, literatura técnica, catálogos comerciais, feiras e exposições, entre muitas outras.

A literatura dominante sobre inovação tecnológica, embora reconheça a necessidade de trabalhar com diversas fontes de idéias, apresenta um viés marcado pela busca de idéias geniais que resultem em inovações com elevado grau de novidade em relação ao estado-da-arte do setor onde ela se aplica. Daí a ênfase em métodos voltados para estimular a geração de idéias geniais, como brainstorming, pensamento lateral, mapeamento contextual, método delphi, análise de cenários, árvore de relevância, curvas de substituição e outros. Esses métodos são transmitidos por meio de treinamentos especiais aos profissionais envolvidos diretamente nos projetos de inovação como os de Pesquisa e Desenvolvimento, marketing, desenvolvimento de produtos e engenharia de processo.

Os meios estruturados para estimular a geração de idéias de funcionários não engajados diretamente nessas atividades, como os sistemas de sugestões, receberam pouca atenção dessa literatura por serem associados às inovações incrementais ou melhorias de pequena monta em produtos e processos existentes, em geral conduzidas por profissionais das áreas de produção e operações. Esse tipo de inovação sempre foi objeto de atenção das áreas produtivas, para as quais foram desenvolvidos diversos métodos, tais como análise de processo, análise do valor, análise de falhas, dentre outros. Com o movimento pela qualidade esse tipo de inovação teve uma valorização surpreendente e passou a ser um dos pilares na qual a qualidade se assentaria. A melhoria contínua não é outra coisa que inovações incrementais realizadas em bases sistemáticas. Não é de estranhar, 
portanto, que as origens dos sistemas de sugestões e seus desenvolvimentos posteriores se encontram nas áreas relacionadas com a gestão de produção e operações.

\section{Sistema de sugestões}

Conforme a JHRA (1997; pg. 217), uma das maiores divulgadoras desses sistemas, a solicitação de sugestões aos funcionários foi usada pela primeira vez na Escócia no século XIX para reduzir o custo da construção de navios. Henry Ford (1925, pg. 133) estabeleceu um sistema voluntário de informação pelo qual qualquer operário podia comunicar qualquer idéia e tentar a sua realização. Segundo suas palavras, com a produção em massa, uma economia de um centavo em cada peça excederia a milhões de dólares por ano. Nessa fase inicial, estes sistemas requeriam pouca ou nenhuma atenção do ponto de vista administrativo, inclusive porque não tinham contra indicações, isto é, se aparecessem idéias, ótimo, se não, também não havia custado nada solicitá-las.

Os sistemas de sugestões foram adotados por um grande número de empresas nos Estados Unidos antes da 2a Guerra Mundial, segundo Yasuda (1991). Ao final da guerra, houve um crescimento vertiginoso do número de empresas com sistemas de sugestões no Japão, tendo contribuído para isso de forma especial a Toyota, então uma pequena empresa, que implantou o seu sistema de sugestões em 1.951 com o nome de Idéia Criativa. Em 1977 o sistema da Toyota atingiu a marca acumulada de um milhão de idéias; em 1984, 10 milhões e 20 milhões em 1988, com uma média de 47,7 idéias por funcionário ano Toyota (YASUDA; p. 69-71). Uma situação completamente diferente ocorreu com o sistema de sugestões da Ford Motor Co, que servira inicialmente de modelo para a Toyota. O sistema da Ford declinou ano a ano e finalmente desapareceu devido à crescente demanda pelo aumento da remuneração pelos geradores de idéias. Originalmente o gerador de uma idéia aceita recebia $10 \%$ do benefício anual proporcionado pela idéia, mas quando os empregados passaram a exigir pagamentos equivalentes a 50\%, a administração da Ford descontinuou o sistema de sugestões (YASUDA, 1991; p. 72).

A literatura especializada apresenta duas abordagens aos sistemas de sugestões. Schuring e Luijten (2001), falam em sistema tradicional e sistema no contexto do kaizen: o primeiro é o sistema da caixa de sugestões que corresponde ao sistema baseado na abordagem ocidental ou norte-americana pela denominação da JHRA; o segundo, ao sistema de sugestões japonês ou oriental, também segundo a JHRA.

A abordagem denominada tradicional, ocidental ou norte-americana caracteriza-se pela busca de idéias geniais estimuladas por recompensas econômicas (ideas pay off ou cash for your idea). A forma de remuneração ao gerador da idéia aprovada pode ser uma quantia em dinheiro negociada caso a caso ou por meio de um percentual previamente estabelecido sobre os ganhos da 
empresa com a implementação da idéia. Nos Estados Unidos a remuneração costumava representar 10\% da economia resultante da sugestão (YASUDA, 1991; p.73). As idéias são analisadas para verificar se trazem benefícios para empresa e para quantificar os benefícios para efeito de remunerar o seu gerador. A aprovação da idéia e a autorização para sua implementação dependem da alta administração, valendo-se de comissões para análise das idéias, sempre levando em conta os ganhos econômicos que a empresa poderá ter com a sua implementação vis-à-vis aos investimentos necessários para implementá-la. Por isso, os processos de aprovação e implantação são complexos e demorados, pois objetivam verificar a viabilidade técnica e econômica da sugestão e estabelecer o prêmio ao seu gerador.

Nesse tipo de sistema somente as idéias que geram benefícios importantes e mensuráveis são consideradas e se aprovadas seguem adiante como qualquer outra idéia selecionada, ou seja, a sua implementação é feita mediante um projeto de inovação e, como tal, com recursos, metas e tempos definidos. O chamamento e a captação de idéias não requer mudanças no modelo de gestão da empresa, embora possa requerer a designação de pessoas encarregadas para receber as idéias e encaminhar para avaliadores. Como diz Böhmerwald (1996; pg. 153), esses sistemas são menos exigentes em termos de gestão, pois geram um número reduzido de idéias e deixam aos empregados a iniciativa de gerar idéias estimuladas por recompensas pecuniárias. Essa abordagem pode ser implementada sem uma vinculação direta com o modelo de gestão da organização.

A abordagem denominada japonesa ou oriental baseia-se na contribuição voluntária de todos os funcionários. As sugestões são estimuladas por recompensas simbólicas com o objetivo de reforçar a coesão interna, pois entende que a busca de recompensas financeiras produz divisões e antagonismos entre os funcionários. A contrapartida da empresa não se restringe a recompensas simbólicas, envolve também recompensas econômicas, não individualizadas como na abordagem anterior, mas coletivas como estabilidade do emprego, distribuição de lucros e resultados, oportunidade de crescimento profissional, ambiente de trabalho seguro, dentre outras. Tanto a empresa quanto os empregados visam resultados econômicos, só que esses vêm em decorrência de um ambiente de trabalho que permite aproveitar oportunidades de melhorias de qualquer tipo, inclusive as minúsculas. Na opinião de Godfrey (2003), ao final, os resultados econômicos acabam sendo superiores aos obtidos pelos sistemas do tipo ocidental que se interessam apenas pelas grandes idéias. A JHRA (1992) usa a palavra teian (proposta) para denominar o sistema de sugestões segundo esta abordagem. O objetivo do sistema é produzir um clima favorável à participação de todos os funcionários na solução dos problemas do dia-a-dia conduzindo à melhoria continua (kaizen) formando desse modo a expressão teian kaisen. Quanto maior a participação das pessoas, maior será a acumulação gradual de pequenos conhecimentos que é a filosofia do kaizen. 
Para Imai (1.988), kaizen significa melhoramento contínuo envolvendo todos, administradores e operários, em todas as instâncias da vida. Esse autor ressalta que o termo kaizen, enquanto melhoramento é um conceito genérico que se aplica a todas as atividades de todos (pg. 8). Esse autor distingue o dois tipos de kaizen, um orientado para pessoas e outro para grupos: o primeiro se manifesta na forma de sugestões individuais e o instrumento para colocá-lo em prática é o sistema de sugestões; o círculo de controle da qualidade é um exemplo de kaizen orientado para grupos (IMAI; p. 83 p. 99). Um CCQ é constituído por pessoas que trabalham na mesma unidade e que se reúnem voluntariamente para resolver problemas da unidade, sugerindo idéias, avaliando-as, implementando-as ou ajudando a implementar. Atribui-se à Ishikawa a criação dos CCQ no Japão no início da década de 1960, porém desde a década de 1940 havia em algumas empresas norteamericanas grupos de trabalhadores organizados de modo voluntário para resolver problemas de qualidade, como mostra James (1996; p. 75). Em princípio, cada CCQ é formado por um grupo pequeno, por isso, é comum observar mais de um CCQ na mesma unidade, principalmente quando ela possui diversas áreas operacionais ou muitos funcionários. Entre os seus principais objetivos estão as melhorias da qualidade, da segurança do trabalho, redução de custo e de todo tipo de desperdícios, ao mesmo tempo em que melhora as relações interpessoais.

A abordagem japonesa ou oriental coloca grandes desafios do ponto de vista de gestão. $\mathrm{O}$ pessoal precisa estar permanentemente motivado para dar sugestões de todos os tipos, o esperado é o recebimento de grande quantidade de idéias por mês, que por sua vez exige suporte administrativo específico para dar respostas rápidas e adequadas aos geradores de idéias e não frustrar suas expectativas. A quantidade de idéias por mês, independentemente do que sejam, é um critério importante de desempenho do sistema, e quanto mais idéias melhor, pois indica que o pessoal está motivado e o sistema está sendo bem gerido. A porcentagem de idéias implementadas é outro critério importante, pois mostra a pertinência das ideais para a empresa, a motivação do pessoal, o envolvimento das chefias e a flexibilidade que eles possuem para tomar decisões. Por isso, o sistema de sugestões deve ser bem estruturado e integrado com o sistema de gestão global da empresa, a partir do comprometimento efetivo da alta administração. A gestão do sistema é descentralizada, todos os chefes possuem autoridade para aprovar e implantar as idéias de seus subordinados aplicáveis ao seu setor. Tanto o sistema orientado para pessoas quanto para grupos requerem um estilo de gestão participativo que valoriza os conhecimento dos funcionários de qualquer área, função ou nível hierárquico. O Quadro 1 resume as características das duas abordagens extraídas dos autores citados. 
Quadro 1: Sistemas de Sugestão: Tipos de Abordagens

\begin{tabular}{|c|c|c|}
\hline Características & $\begin{array}{c}\text { TRADICIONAL } \\
\text { (outras denominações: ocidental e } \\
\text { norte-americana) }\end{array}$ & $\begin{array}{c}\text { JAPONÊS } \\
\text { (outras denominações: oriental, kaizen e teian } \\
\text { kaizen) }\end{array}$ \\
\hline Objetivo & $\begin{array}{l}\text { Captar idéias com alta probabilidade de } \\
\text { gerarem inovações de sucesso. }\end{array}$ & $\begin{array}{l}\text { Ampliação da comunicação e do } \\
\text { relacionamento entre o pessoal interno e a } \\
\text { diretoria. Instrumento de educação } \\
\text { permanente de todo pessoal mediante o } \\
\text { acúmulo gradual de pequenos conhecimentos. }\end{array}$ \\
\hline $\begin{array}{l}\text { Número de } \\
\text { idéias geradas }\end{array}$ & $\begin{array}{l}\text { Não é importante, mas sim os resultados } \\
\text { que podem trazer para a empresa. }\end{array}$ & $\begin{array}{l}\text { Muito importante, pois são indicadores de } \\
\text { participação. O declínio do número de } \\
\text { sugestões é sempre visto com preocupação, } \\
\text { pois sinaliza refluxo da participação. }\end{array}$ \\
\hline Participantes & $\begin{array}{l}\text { Poucas pessoas, geralmente com elevado } \\
\text { grau de instrução ou de capacitação } \\
\text { técnica. }\end{array}$ & $\begin{array}{l}\text { Participação do maior número possível de } \\
\text { empregados, independentemente das funções } \\
\text { que ocupam e dos cargos que exercem. }\end{array}$ \\
\hline Recompensa & $\begin{array}{l}\text { Premiações em dinheiro de acordo com o } \\
\text { impacto da idéia para os objetivos da } \\
\text { empresa. Em geral um percentual sobre o } \\
\text { benefício que a empresa irá auferir com a } \\
\text { implantação da idéia. }\end{array}$ & $\begin{array}{l}\text { Premiações simbólicas. A recompensa } \\
\text { econômica é coletiva, obtida pela estabilidade } \\
\text { do emprego, situação econômica favorável } \\
\text { que permite distribuir lucros e resultados etc. }\end{array}$ \\
\hline $\begin{array}{l}\text { Normas que } \\
\text { regem o } \\
\text { sistema }\end{array}$ & $\begin{array}{l}\text { Sistema regido por normas complexas e } \\
\text { detalhadas, com muitas etapas e } \\
\text { diferentes critérios para aferir resultados. }\end{array}$ & $\begin{array}{l}\text { Sistema regido por normas simples e pouco } \\
\text { detalhada e aplicadas de forma } \\
\text { descentralizada. }\end{array}$ \\
\hline $\begin{array}{l}\text { Aprovação das } \\
\text { sugestões }\end{array}$ & $\begin{array}{l}\text { Aprovação da idéia e a autorização para a } \\
\text { sua implementação dependem da Alta } \\
\text { Direção. }\end{array}$ & $\begin{array}{l}\text { As chefias possuem autoridade para aprovar e } \\
\text { implantar as sugestões de seus subordinados } \\
\text { aplicáveis ao seu setor. }\end{array}$ \\
\hline $\begin{array}{l}\text { Gestão do } \\
\text { sistema }\end{array}$ & $\begin{array}{l}\text { Gestão centralizada na Alta } \\
\text { Administração, usando comissões para } \\
\text { análise das idéias. }\end{array}$ & $\begin{array}{l}\text { Gestão descentralizada envolvendo todas as } \\
\text { áreas e níveis da organização. }\end{array}$ \\
\hline
\end{tabular}

Fonte: elaboração própria com base nos autores citados nessa seção.

\section{A pesquisa}

O objetivo da pesquisa foi estudar os sistemas de sugestões em três empresas brasileiras reconhecidas como inovadoras e que possuem sistemas de sugestões atuantes, bem geridos e que atendem as expectativas para os quais foram criados. Cada uma possui sistema de sugestões com características próprias. Usou-se para isso o método do estudo de casos, pois permite identificar as decisões de gestão relacionadas com o desempenho dos sistemas de sugestões dentro de uma realidade complexa, bem como descrever o contexto dessa realidade e explorar situações que não estão claramente definidas (YIN, 2001), por exemplo, as motivações para criar os sistemas e as articulações com o modelo de gestão global. O método também é apropriado para confrontar uma realidade específica com os conceitos discutidos na revisão conceitual, bem como para revelar aspectos novos sobre os temas tratados. Para Eisenhardt (1989), este método é uma estratégia de pesquisa que permite ao pesquisador compreender a dinâmica de contextos específicos e pode ser usado para confirmar, estender e refinar teorias existentes (p. 533-4). Em cada sistema selecionado 
foi feito um estudo em profundidade do seu modelo de gestão geral e do seu sistema de sugestões. O relato a seguir é um resumo da pesquisa efetuada entre 2005 e 2007.

\subsection{Projeto Simplificação}

A Brasilata S/A Embalagens Metálicas, produtora de embalagens de latas de aço, fundada em 1955 na cidade de São Paulo, contava com 900 funcionários no momento da pesquisa, distribuídos em três unidades fabris nos estados de São Paulo, Rio Grande do Sul e Goiás. Seu capital é totalmente nacional e é a terceira empresa de um setor. Com a recessão dos anos 1982 e 1983 a lucratividade do setor caiu como um todo e a partir daí começa um processo de reestruturação da empresa, com a adoção das técnicas japonesas de administração participativa em 1985, iniciando com a introdução de práticas just in time (JIT) do produto em processo (sistema kanban), nas quais o envolvimento e a participação dos operadores é uma condição indispensável para o seu funcionamento. Isso tornava necessário abrir canais de comunicação com os funcionários. Para isso, foi criado o sistema de sugestões denominado Projeto Simplificação no final de 1987, como parte de uma mudança mais ampla na qual os objetivos da empresa foram reescritos de forma participativa, com a colaboração de diretores, gerentes e supervisores. Definiuse nesse momento relacionamentos de longo prazo estabelecendo para os acionistas uma política baseada na excelência na lucratividade; para os funcionários, uma política de não demissão; para os clientes, o contingenciamento nas crises; e para os fornecedores, uma relação de parceria.

O Projeto Simplificação é um sistema de sugestões com base em premiação simbólica. A recompensa econômica é coletiva e se dá pela política de não demissão estabelecida em 1988, pelo sistema de participação dos empregados nos resultados da empresa que vigora desde 1991, implantado quatro anos antes da Lei que estabeleceu a sua obrigatoriedade. O sistema é administrado em cada unidade da Brasilata por uma equipe que se reporta diretamente ao Diretor Superintendente. A coordenação de cada equipe é feita pela pessoa que exerce na sua unidade a chefia da Coordenadoria de Desenvolvimento Pessoal, um órgão de Recursos Humanos. Cada equipe é composta por um auxiliar técnico, um auxiliar administrativo, um eletricista e dois mecânicos e conta também com apoio indireto de cinco pessoas no mínimo que atuam de modo voluntário. As sugestões chegam pelo sistema on line ou pela coleta nas caixas espalhadas pela unidade e passam por exame formal de validação para verificar se a sugestão está completa. As sugestões são avaliadas pelos coordenadores das áreas onde elas se aplicam num prazo máximo de 7 dias. Se for aprovada a chefia da área tem 30 dias para implantá-la. Os critérios de para a aprovação são aplicabilidade da idéia e a relação benefício-custo, segundo as seguintes faixas: 
(a) Idéias que implicam até $\mathrm{R} \$ 100,00$ de custo, o avaliador (que é o responsável pela área onde a idéia será aplicada) tem autonomia para aprovar;

(b) Idéias que impliquem em custos entre $\mathrm{R} \$ 100,01$ a $\mathrm{R} \$ 1.000,00$ cabe ao gerente da unidade a aprovação;

(c) Idéias acima de $\mathrm{R} \$ 1.000,01$ devem seguir o roteiro normal de qualquer gasto com investimento, respeitando os limites orçamentários da unidade.

(d) Idéias que se aplicam á empresa como um todo são avaliadas pela diretoria de acordo com os critérios de segurança, economia, execução e espaço, nessa ordem de prioridade.

Idéias repetidas ou que não atendem esses critérios não são aprovadas e as razões são comunicadas. Para gerir o sistema e dar transparência às suas decisões foi desenvolvido um software específico. O acesso ao sistema é livre para qualquer funcionário que pode navegar pelas suas telas para verificar o status das suas idéias, enviar idéias á equipe, obter totalizações das idéias por área, por unidade etc. A tabela 1 apresenta o número de idéias geradas nos últimos anos.

Tabela 1: Projeto Simplificação: Número de Idéias e idéias por funcionário/ano $(2.001-06)$

\begin{tabular}{cccc}
\hline Ano & Número de idéias & Idéias por funcionário/ano & Percentagem de aprovação \\
\hline 2001 & 2.453 & 2,7 & $43 \%$ \\
2002 & 10.387 & 11,6 & $47 \%$ \\
2003 & 28.940 & 31,8 & $43 \%$ \\
2004 & 31.922 & 34,3 & $62 \%$ \\
2005 & 45.364 & 48,7 & $82 \%$ \\
2006 & 105.402 & 121,1 & $90 \%$ \\
\hline
\end{tabular}

Fonte: Relatório interno da empresa

Esse sistema de sugestões apresenta características aderentes ao tipo japonês orientado para pessoas, no qual espera-se que surjam muitas idéias e com um percentual elevado de implementações. O Projeto Simplificação confirma o que a literatura consultada coloca como pontos centrais do sucesso desse sistema: (1) a resposta rápida ao gerador da idéia, seja aprovada ou não, e (2) a rápida implementação das idéias aprovadas. Para isso, o sistema tem de ser descentralizado no nível da avaliação e execução e gerido de forma ágil e transparente. Dar respostas rápidas a milhares de novas sugestões por mês é um dos seus principais desafios, pois dele depende a possibilidade de manter o pessoal constantemente motivado para gerar números expressivos de sugestões continuamente. Porém, a motivação maior depende do modelo geral de gestão da empresa, envolvendo suas prática e compromissos, como os citados acima, que são percebidos como formas de recompensas econômicas pelos funcionários.

Como se verificou, a maioria das idéias está associada às inovações incrementais, porém, o sistema também gerou idéias com novidades radicais que foram trabalhadas por equipes específicas 
que as transformaram em invenções para as quais foram requeridas proteções patentária em diversos países, dentre eles os Estados Unidos, cujo órgão de patente se caracteriza pelo rigor na avaliação do requisito da novidade. O número de patentes dessa empresa é expressivo, mais de 50, sendo que algumas delas foram licenciadas para outras empresas, um fato notável considerando que ela atua num setor dependente dos fornecedores de tecnologia, conforme a tipologia de Bell; Pavitt (1993). De fato, a forma típica de inovação tecnológica das empresas do setor de embalagens de latas se dá mediante aquisição de bens de capital, insumos e serviços que incorporam novos conhecimentos produzidos em outros setores. A empresa, no entanto, é reconhecida como inovadora como atesta centenas de prêmios recebidos no Brasil e no exterior e o prêmio da FAPESP de empresa inovadora em sua categoria no ano de 2005 e 2008.

\subsection{Sistema de Sugestões Baseado em Grupos}

A WEG SA, empresa de capital brasileiro criada em 1.961 em Jaraguá do Sul no Estado de Santa Catarina, é reconhecida nacional e internacionalmente pela sua capacidade inovadora nos ramos em que atua. Exporta para mais de 70 países. Esta empresa também começou a introduzir técnicas gerenciais participativas segundo os modelos japoneses a partir da crise de meados dos anos 1980, incluindo um sistema de participação dos empregados nos lucros e resultados. O sistema de sugestão desta empresa é baseado no conceito de kaizen orientado para grupos sob a forma de círculos de controle de qualidade (CCQ). Seus CCQs foram criados em 1.982; em 2006 havia 410 deles, 80\% nas áreas produtivas e 20\% nas administrativas. Até 2006 eles geraram 55.177 idéias implantadas, sendo $34 \%$ sobre ambiente de trabalho; $27 \%$ sobre qualidade; $18 \%$, custos e $21 \%$ sobre questões diversas.

Neste tipo de sistema de sugestões, o numero de idéias também é um indicador relevante, apesar de não se comparar com o número gerado pelo sistema orientado para pessoas. Isso porque os sistemas deste tipo captam qualquer idéia, enquanto os CCQ filtram as sugestões de interesse para a unidade a qual estão vinculados no intervalo entre uma reunião e outra para se dedicar àquelas de maior relevância para o momento em termos de redução de custo e de riscos, melhoria da qualidade, prevenção da poluição e outras considerações do gênero. É comum a captação de sugestões de colegas não pertencentes ao grupo, mas considerada importante por este. A empresa mantém um canal aberto on line para que qualquer funcionário apresente suas sugestões. Como as sugestões relacionadas com as atividades administrativas e operacionais são encaminhadas via CCQs, esse canal é usado basicamente para reivindicações e outras solicitações, cumprindo uma função de canal de comunicação com a diretoria.

A implantação de um CCQ é sempre de caráter voluntário e uma vez criado, por iniciativa das pessoas que irão compô-lo, deve prevalecer o princípio da não obsessão por resultado, 
significando que não pode haver cobrança de resultados. Aliás, este é corolário daquele, pois a cobrança de resultados retiraria o caráter voluntário da iniciativa. $\mathrm{O}$ apoio gerencial e um ambiente favorável à participação são condições essenciais para o funcionamento adequado dos círculos. As reuniões de cada CCQs, em geral uma por mês, como mostra a tabela 2, são conduzidas por líderes e qualquer participantes pode se tornar líderes do seu grupo. O funcionamento do círculo é formalizado, desde a convocação da reunião até o encerramento, no qual o grupo deve elaborar uma ata da reunião e enviar ao setor que os coordena no prazo não superior a 15 dias consecutivos da data da reunião.

Tabela 2: número de CCQ’s e Idéias Geradas

\begin{tabular}{|c|c|c|c|c|c|c|}
\hline \multirow[t]{2}{*}{ Ano } & \multirow[t]{2}{*}{ Grupos } & \multirow{2}{*}{$\begin{array}{c}\text { média de } \\
\text { reuniões }\end{array}$} & \multirow{2}{*}{$\begin{array}{l}\text { total de } \\
\text { idéias }\end{array}$} & \multicolumn{2}{|c|}{ Idéias Aprovadas } & \multirow{2}{*}{$\begin{array}{c}\text { Idéias } \\
\text { rejeitadas }\end{array}$} \\
\hline & & & & Implementadas & não implementadas & \\
\hline 2002 & 336 & 13 & 4.636 & 3.766 & 436 & 434 \\
\hline 2003 & 360 & 13 & 4.767 & 3.905 & 436 & 426 \\
\hline 2004 & 392 & 12 & 4.664 & 3.675 & 606 & 383 \\
\hline 2005 & 397 & 12 & 4.967 & 3742 & 670 & 555 \\
\hline 2006 & 410 & 12 & 5.482 & 4152 & 835 & 495 \\
\hline
\end{tabular}

O plano de motivação do CCQ envolve três conjuntos de ações: a exposição do CCQ realizada no mês de maio, quando cada grupo expõe um trabalho; o sistema de premiação no qual 26 grupos são selecionados pela qualidade do trabalho e 20 recebem prêmios na forma de viagens; e reconhecimento por desempenho premiando grupos com viagens e conferindo brindes individuais. Os trabalhos são julgados pela originalidade da idéia e complexidade do tema em relação à origem e a formação do grupo. O maior desafio é manter os CCQs ativos e isso depende da gestão global da empresa, da mesma forma que o sistema comentado anteriormente. Porém, diferentemente deste, os CCQS exigem treinamentos sobre temas específicos de interesse da unidade em que estão vinculados, bem como para estimular a criatividade, como o brainstorming e outras técnicas estruturadas e para o exercício da liderança. Assim, os grupos acabam se tornando especialistas tanto nos assuntos da sua unidade quanto no processo de geração de idéias.

\subsection{Programa Click}

A Suzano Celulose e Papel mantêm um sistema de sugestões que remunera os geradores de idéias, denominado Programa de Inovação e Criatividade ou Programa Click. Foi criado em 2000, inicialmente na unidade localizada no Município de Mucuri, no extremo sul do Estado da Bahia. Sua criação fez parte de decisões estratégicas para alinhar o modelo de gestão da empresa aos critérios de Excelência do Prêmio Nacional da Qualidade (PNQ), disseminar a cultura da inovação e do intra-empreendedorismo e ampliar o relacionamento entre áreas e funções, considerando que a 
empresa estava migrando de um modelo hierárquico funcional para um sistema matricial pouco hierarquizado.

Todos os empregados, estagiários e trainees, exceto diretores e gerentes, podem propor idéias que, se aprovadas, são premiadas em dinheiro. Vale qualquer idéia desde que vise solucionar problemas ou melhorar algo que resulte em benefício para a empresa ou para os empregados. As idéias podem ser de dois tipos: idéias com retorno financeiro mensurável, que são as que trazem benefícios como receitas ou redução de custos para a empresa, mensuráveis durante o processo da sua avaliação; e idéias com retorno não mensurável, que são as que trazem benefícios para os empregados e para o clima organizacional da empresa sem gerar benefícios econômicos diretamente vinculados a sua implementação. A partir de meados de 2005, o prêmio máximo a ser concedido para idéias do tipo 1 foi fixado em $\mathrm{R} \$ 20.000,00$. No início o limite máximo que de remuneração era de R\$ 10.000,00. Esse é um problema típico desse tipo de sistema: com o tempo o valor dos prêmios perde a capacidade de estimular a geração de idéias e a solução é aumentar o seu valor.

O processo de avaliação de uma idéia inicia com o seu encaminhamento por escrito em formulário próprio, na qual o proponente deve responder o que deve ser melhorado e como pode ser melhorado. Os gerentes das áreas dos processos relacionados à proposta avaliam as idéias com base no conhecimento que possuem sobre os processos envolvidos e as necessidades ou oportunidades de melhoria. Entre os critérios de avaliação estão os seguintes: impacto nos objetivos estratégicos da organização, abrangência da aplicação da proposta, redução de custos, benefícios para a qualidade do produto, aumento da produção e impactos ao meio ambiente, saúde e segurança ocupacional. Uma idéia do tipo 1 só será paga quando o retorno financeiro for comprovado. Calcula-se $10 \%$ do retorno líquido da idéia em 12 meses multiplicado pelo fator pertinente (Tabela 3) e os valores de referência (Tabela 4). Neste aspecto o Programa é aderente ao tradicional ou ocidental, pois a avaliação de uma idéia percorre um fluxo de atividades complexo e detalhado para se certificar de que a sugestão trará retorno para a empresa e calcular a premiação.

Tabela 3: Programa Click: Fatores de Avaliação da Idéias

\begin{tabular}{|c|c|c|c|}
\hline Fator & Significado da medida & Grau da medida & Valor \\
\hline \multirow[t]{3}{*}{ F1 } & \multirow{3}{*}{$\begin{array}{l}\text { Participação do proponente } \\
\text { na implementação da idéia. }\end{array}$} & Coordena a implantação & 2,00 \\
\hline & & Participa da implantação & 1,50 \\
\hline & & Não contribui para a implantação & 1,00 \\
\hline \multirow[t]{2}{*}{$\underline{\mathrm{F} 2}$} & \multirow[t]{2}{*}{ Trabalho em equipes. } & Proposta de grupo & 1,50 \\
\hline & & Proposta individual & 1,00 \\
\hline \multirow[t]{2}{*}{ F3 } & \multirow[t]{2}{*}{ Natureza da idéia } & Tem impacto direto nos objetivos estratégicos & 1,50 \\
\hline & & Tem escopo administrativo ou operacional & 1,00 \\
\hline
\end{tabular}

Fonte: Bahia Sul, Programa Click (s/d)

Tabela 4: Programa Click: Valores de Referencia

\begin{tabular}{lc}
\hline \multicolumn{1}{c}{ Abrangência da aplicação da proposta } & VALOR DE REFERÊNCIA (R\$) \\
\hline Aplica-se em geral para toda a empresa & 200 \\
Aplica-se toda uma diretoria ou unidade. & 150 \\
\hline
\end{tabular}




\begin{tabular}{lc}
\hline Aplica-se a uma gerência ou coordenação & 100 \\
Aplica-se pontualmente. & 50 \\
\hline
\end{tabular}

Fonte: Bahia Sul, Programa Click (s/d)

As idéias sem retorno mensuráveis, tipo 2, são avaliadas qualitativamente, seguindo o esquema apresentado no Quadro 2. A remuneração dessas idéias varia de um mínimo de R\$100,00 até o limite máximo de $\mathrm{R} \$ 600,00$ (Tabela 5). Sob este aspecto o Programa Click difere do sistema tradicional ou norte-americano, segundo denominação da JHRA, pois este só se interessa por idéias que trazem vantagens econômicas significativas. Difere deste também do sistema tradicional no qual a remuneração é calculada como um percentual do benefício que a empresa terá, em geral no primeiro ano após a implementação da idéia, ou o que for acordado entre as partes, ou seja, não há limites para a remuneração como no Programa Click. Porém, mesmo com limites, como mostrados acima, os efeitos sobre o pessoal são semelhantes ao tradicional: estimula a geração de idéias para obter uma remuneração e incentiva a ação individual. As idéias em geral são apresentadas por um indivíduo apenas, poucas são apresentadas por mais de um. Já nos sistemas de sugestões baseados em recompensas simbólicas as idéias são geradas por grupos de pessoas envolvidas formalmente como nos CCQs ou informalmente como no Projeto Simplificação. Neste, cerca de $50 \%$ das idéias são geradas por dois ou mais empregados.

Quadro 2: Critérios Para Análise de Idéias Com Retorno Financeiro Não Mensurável

\begin{tabular}{|c|c|c|c|}
\hline \multirow[b]{2}{*}{ Fator de Avaliação } & \multicolumn{3}{|c|}{ Grau de Relevância da Idéia } \\
\hline & Baixo (1 ponto) & Médio (2 pontos) & Alto (3 pontos) \\
\hline $\begin{array}{l}\text { 1. Abrangência do } \\
\text { aproveitamento da } \\
\text { idéia na Suzano Papel } \\
\text { e Celulose (SPC) }\end{array}$ & $\begin{array}{l}\text { A idéia aplica-se a uma } \\
\text { Divisão de uma certa } \\
\text { Unidade da SPC. }\end{array}$ & $\begin{array}{l}\text { A idéia aplica-se a uma ou } \\
\text { mais Unidade da SPC. }\end{array}$ & $\begin{array}{l}\text { A idéia aplica-se a todas as } \\
\text { unidades da SPC. }\end{array}$ \\
\hline $\begin{array}{l}\text { 2. Contribuição para a } \\
\text { imagem positiva da SPC }\end{array}$ & $\begin{array}{l}\text { A idéia contribui } \\
\text { positivamente para a } \\
\text { imagem da SPC junto a } \\
\text { setores e áreas de atividades } \\
\text { internas. }\end{array}$ & $\begin{array}{l}\text { A idéia contribui para o } \\
\text { fortalecimento da imagem } \\
\text { positiva da SPC junto às } \\
\text { comunidades próximas a } \\
\text { uma ou mais Unidade de } \\
\text { Negócio ou, no máximo, em } \\
\text { nível regional. }\end{array}$ & $\begin{array}{l}\text { A idéia contribui para o } \\
\text { fortalecimento da imagem } \\
\text { positiva da SPC em nível } \\
\text { nacional, ou mesmo } \\
\text { internacional. }\end{array}$ \\
\hline $\begin{array}{l}\text { 3. Sinergia da idéia para } \\
\text { com a visão, a missão, os } \\
\text { valores, as políticas e os } \\
\text { códigos da SPC. }\end{array}$ & $\begin{array}{l}\text { A idéia tem alguma } \\
\text { correlação para com a visão, } \\
\text { a missão, os valores, as } \\
\text { políticas e os códigos da } \\
\text { SPC. }\end{array}$ & $\begin{array}{l}\text { A idéia tem média } \\
\text { correlação para com a visão, } \\
\text { a missão, os valores, as } \\
\text { políticas e os códigos da } \\
\text { SPC. }\end{array}$ & $\begin{array}{l}\text { A idéia tem forte correlação } \\
\text { para com a visão, a missão, } \\
\text { os valores, as políticas e os } \\
\text { códigos da SPC. }\end{array}$ \\
\hline $\begin{array}{l}\text { 4. Importância da idéia } \\
\text { para com a melhoria } \\
\text { das relações da SPC } \\
\text { com as partes } \\
\text { interessadas. }\end{array}$ & $\begin{array}{l}\text { A idéia tem baixa } \\
\text { contribuição para a } \\
\text { melhoria das relações da } \\
\text { SPC com os colaboradores, } \\
\text { órgãos governamentais, } \\
\text { ONGs, clientes, } \\
\text { fornecedores, governo e/ou } \\
\text { sociedade em geral. }\end{array}$ & $\begin{array}{l}\text { A idéia tem media } \\
\text { contribuição para a } \\
\text { melhoria das relações da } \\
\text { SPC com os colaboradores, } \\
\text { órgãos governamentais, } \\
\text { ONGs, clientes, } \\
\text { fornecedores, governo e/ou } \\
\text { sociedade em geral. }\end{array}$ & $\begin{array}{l}\text { A idéia contribui } \\
\text { decisivamente para a } \\
\text { melhoria das relações da } \\
\text { SPC com os colaboradores } \\
\text { ou com comunidades, } \\
\text { órgãos governamentais, } \\
\text { ONGs, clientes, } \\
\text { fornecedores, governo e/ou } \\
\text { sociedade em geral. }\end{array}$ \\
\hline $\begin{array}{l}\text { 5. Facilidade técnico- } \\
\text { financeira para a } \\
\text { implantação da idéia. }\end{array}$ & $\begin{array}{l}\text { A idéia, para ser } \\
\text { implantada, encontra } \\
\text { obstáculos técnicos e/ou } \\
\text { financeiros muito } \\
\text { complexos. }\end{array}$ & $\begin{array}{l}\text { A idéia, para ser } \\
\text { implantada, requer esforço } \\
\text { técnicos e/ou investimentos } \\
\text { razoáveis (custos x } \\
\text { benefícios). }\end{array}$ & $\begin{array}{l}\text { A idéia é facilmente } \\
\text { implementável do ponto de } \\
\text { vista técnico e financeiro. }\end{array}$ \\
\hline
\end{tabular}

Fonte: Documento do Click. 
Tabela 5: Equivalência de pontos em valores $(\mathrm{R} \$)$

\begin{tabular}{cccccc}
\hline Pontos & R $\$$ & Pontos & R & Pontos & R $\$$ \\
\hline 5 & 100,00 & 8 a 9 & 300,00 & 12 a 13 & 500,00 \\
6 a 7 & 200,00 & 10 a 11 & 400,00 & 14 a 15 & 600,00 \\
\hline
\end{tabular}

Fonte: Documento do Click.

\section{Discussão}

Com base nesse estudo, verificou-se que os tipos de sistemas de sugestões e suas denominações extraídas da literatura necessitam reparos. Essa literatura esteve ligada ao movimento da qualidade que teve um forte impulso com o sucesso das empresas japonesas numa determinada época e, por conseguinte, das suas técnicas gerenciais e operacionais em contraposição das técnicas desenvolvidas no ocidente. $\mathrm{O}$ que se denomina de sistema japonês ou oriental foi valorizado pelo Movimento de Relações Humanas e nos estudos sobre qualidade, ambos desenvolvidos no ocidente. Depois, foi transladado para o Japão no pós-guerra, onde adquiriu uma importância sem precedentes e muito das suas características atuais. Hoje, este tipo de sistema encontra-se difundido no mundo todo, o que mostra que não se trata de algo exclusivo ao ambiente japonês. Os aspectos culturais dos países que deram origem ou a feição dominante não tiveram relevância no processo de difusão desse tipo de sistema, pois foi adotado com êxito em todos lugares, como mostram Basadur (1997, pg. 72) e Bonache (2000; pg. 38). Dada a sua difusão universal e sua dupla origem melhor seria denominá-lo sistema de sugestões participativo, no qual o adjetivo participativo denota uma das suas características essenciais. Outras características estão resumidas no Quadro 3. O Projeto Simplificação e os círculos de controle da qualidade se enquadram neste tipo.

Quadro 3: Sistemas de Sugestões: Tipologia Proposta

\begin{tabular}{|l|l|l|l|}
\hline \multirow{2}{*}{$\begin{array}{l}\text { Tipo de } \\
\text { Características }\end{array}$} & \multicolumn{1}{c|}{$\begin{array}{c}\text { SUGESTÕES } \\
\text { REMUNERADAS }\end{array}$} & \multicolumn{1}{c|}{ EM GRUPO } & \multicolumn{1}{c|}{ INDIVIDUAL } \\
\cline { 2 - 4 } & $\begin{array}{l}\text { Estimular a geração de idéias } \\
\text { que gerem benefícios } \\
\text { econômicos, bem como } \\
\text { contribuições à melhoria do } \\
\text { ambiente de trabalho e das } \\
\text { relações com as partes } \\
\text { interessadas. }\end{array}$ & $\begin{array}{l}\text { Estimular melhoria } \\
\text { contínua por meio de } \\
\text { grupos com ações } \\
\text { localizadas nos seus } \\
\text { setores de trabalho. } \\
\text { Promover a educação } \\
\text { permanente de todo } \\
\text { pessoal mediante o } \\
\text { acúmulo gradual de } \\
\text { pequenos conhecimentos }\end{array}$ & $\begin{array}{l}\text { Estimular a geração de } \\
\text { idéias por meio da } \\
\text { ampliação da comunicação } \\
\text { e do relacionamento entre o } \\
\text { pessoal interno e a diretoria. } \\
\text { Promover a educação } \\
\text { permanente de todo pessoal } \\
\text { mediante o acúmulo gradual } \\
\text { de pequenos conhecimentos. }\end{array}$ \\
\hline $\begin{array}{l}\text { Número de } \\
\text { idéias geradas }\end{array}$ & $\begin{array}{l}\text { O mais importante são os } \\
\text { resultados econômicos e a } \\
\text { relação entre benefícios } \\
\text { obtidos e prêmios concedidos. }\end{array}$ & $\begin{array}{l}\text { Muito importante, pois são indicadores de participação. } \\
\text { O declínio do número de sugestões é sempre visto com } \\
\text { preocupação, pois sinaliza refluxo da participação. }\end{array}$ \\
\hline Participantes & \multicolumn{2}{|c|}{$\begin{array}{l}\text { Participação do maior número possível de empregados, independentemente das funções } \\
\text { que ocupam e dos cargos que exercem. }\end{array}$} \\
\hline
\end{tabular}




\begin{tabular}{|c|c|c|c|}
\hline Recompensa & $\begin{array}{l}\text { Premiações em dinheiro de } \\
\text { acordo com o impacto da idéia } \\
\text { para os objetivos da empresa, } \\
\text { limitadas a um valor máximo. }\end{array}$ & \multicolumn{2}{|c|}{$\begin{array}{l}\text { Premiações simbólicas. A recompensa econômica é } \\
\text { coletiva, obtida pela estabilidade do emprego, situação } \\
\text { econômica favorável que permite distribuir lucros e } \\
\text { resultados, oportunidade de crescimento profissional etc. }\end{array}$} \\
\hline $\begin{array}{l}\text { Normas que } \\
\text { regem o } \\
\text { sistema }\end{array}$ & $\begin{array}{l}\text { Sistema regido por normas } \\
\text { complexas, detalhadas, com } \\
\text { muitas restrições, etapas e } \\
\text { critérios para aferir os } \\
\text { resultados. }\end{array}$ & $\begin{array}{l}\text { Sistema regido por } \\
\text { normas simples para } \\
\text { aplicação em todas as } \\
\text { áreas da organização por } \\
\text { meio de grupos } \\
\text { formalmente } \\
\text { constituídos. }\end{array}$ & $\begin{array}{l}\text { Sistema regido por normas } \\
\text { simples com pouco } \\
\text { detalhamento para serem } \\
\text { aplicadas de forma } \\
\text { descentralizada a todas as } \\
\text { áreas da organização por } \\
\text { meio de pessoas. }\end{array}$ \\
\hline $\begin{array}{l}\text { Aprovação das } \\
\text { sugestões }\end{array}$ & $\begin{array}{l}\text { O responsável pelo processo, } \\
\text { produto ou serviço onde a idéia } \\
\text { se aplica. Esta pessoa pode não } \\
\text { ser o avaliador da idéia. }\end{array}$ & \multicolumn{2}{|c|}{$\begin{array}{l}\text { As chefias possuem autoridade para aprovar e implantar } \\
\text { as sugestões de seus subordinados aplicáveis ao seu } \\
\text { setor. }\end{array}$} \\
\hline $\begin{array}{l}\text { Gestão do } \\
\text { sistema }\end{array}$ & $\begin{array}{l}\text { Centralizada nos gerentes que } \\
\text { aprovam as idéias, calculam os } \\
\text { benefícios líquidos e se } \\
\text { encarregam da implantação. }\end{array}$ & $\begin{array}{l}\text { Centralizada no líder do } \\
\text { grupo. }\end{array}$ & $\begin{array}{l}\text { Descentralizada envolvendo } \\
\text { pessoas de todas as áreas e } \\
\text { níveis da organização. }\end{array}$ \\
\hline
\end{tabular}

Fonte: elaboração própria com base em vários autores citados neste texto e nos resultados da presente pesquisa.

Quanto ao sistema de sugestões que os textos denominam tradicional, ocidental ou norteamericano, a primeira denominação seria a mais correta, pelos mesmos motivos apresentados acima. Porém, na sua forma pura, como a literatura retrata, é um sistema extinto que não mais se observa na prática enquanto meio para gerar e captar idéias dos empregados. Idéias remuneradas com base em percentual do benefício econômico para a empresa ocorrem, mas de forma esporádica, senão rara, de modo que são tratadas caso a caso. Por isso, os esforços associados a elas não constituem um sistema de gestão propriamente dito. Assim, na tipologia aqui proposta esse modo de estimular a geração idéias não foi considerado.

O que se observa é uma variante desse sistema, aqui denominado sistemas de sugestões remuneradas, pois o atrativo proporcionado pela remuneração é que induz à geração de idéias. A remuneração é uma característica essencial desse tipo de sistema. No entanto, ao estabelecer um limite máximo de remuneração, elimina-se a relação direta entre a recompensa e o ganho proporcionado à empresa como na abordagem tradicional. O sistema tradicional se preocupa apenas com sugestões que trazem benefícios econômicos mensuráveis, pois quando surgiu, no século XIX, esse era o seu objetivo e a visão de benefícios para a empresa não contemplava outra perspectiva que não fosse algo medido em valores monetários. O Programa Click também remunera idéias que contribuem para melhorar o ambiente da organização sem que se possa relacioná-la diretamente a ganhos econômicos mensuráveis. A inclusão desse tipo de idéia é coerente com o estágio atual de valorização dos ativos intangíveis. Da abordagem tradicional permanecem no sistema remunerado as seguintes características ressaltada na literatura consultada: é regido por normas complexas e detalhadas para efeito de avaliação e premiação e é gerido com maior grau de centralização comparativamente aos sistemas participativos. 


\section{Considerações finais}

As decisões concernentes à criação e operação de um sistema de sugestões de acordo com as tipologias apresentadas no Quadro 3 devem ser encaradas como estratégicas. Todos eles exigem gestão específica integrada ao modelo de gestão global da organização. Eles mobilizam a organização inteira e geram expectativas de acordo com o tipo de recompensa. Para a empresa que adota um sistema de sugestões remuneradas, passar para um sistema participativo pode ficar inviabilizado pelas expectativas de ganhos proporcionados pelo sistema de recompensa. Se a transição for do sistema participativo para o remunerado a expectativa de ganho individual pode comprometer a coesão interna. Manter dois sistemas diferentes na mesma organização é possível se ambos forem do tipo participativo. Porém, não há convivência pacífica entre um sistema deste tipo e um de sugestões remuneradas. A expectativa de ganhos financeiros individualizados tende a eliminar as contribuições voluntárias recompensadas simbolicamente.

Os casos analisados mostram que as sugestões encaminhadas pelos sistemas estudados, via de regra, geram inovações incrementais. Desse fato decorre a pouca atenção dada a estes sistemas na literatura sobre gestão da inovação, mais interessada em inovações radicais. Nas últimas décadas do século passado, as estratégias baseadas em inovações incrementais ganharam inimigos de pesos. Negroponte, pesquisador do MIT Média Lab, com muita visibilidade no ambiente empresarial, afirmou que o incrementalismo é o pior inimigo da inovação, e essa frase foi repetida $a d$ nauseam por Tom Peter, autor de obras bastante populares nesse ambiente. E não são os únicos. Esse tipo de crítica não é totalmente desprovido de razão, pois as inovações incrementais voltam-se preferentemente para o que se está fazendo no momento para fazer melhor e com menor custo, enquanto as ameaças mais graves para as empresas estão associadas às inovações radicais que introduzem novos produtos, modificam o modo de competir ou criam novos setores econômicos. Por exemplo, a injeção eletrônica não veio do aperfeiçoamento do carburador. Por isso, basear a estratégia competitiva apenas em mudanças incrementais é desaconselhável e sob este aspecto estão certos os autores citados. Mas isso não elimina a importância das inovações incrementais, ao contrário, quanto mais elas são realizadas, mas se aproxima do conceito de melhoria contínua, um dos conceitos mais importantes desenvolvidos pelo movimento da qualidade. Os sistemas de sugestões estudados contribuem de modo significativo para o aumento vigoroso das inovações incrementais, o que os torna instrumentos para implementar melhorias continuamente e, desse modo, contribuem para que as empresas realizem suas atividades atuais de modo mais eficiente.

Muitas idéias estimuladas pelos sistemas de sugestão estudados são geradoras de benefícios econômicos importantes, bem como inovações radicais. Isso é algo sempre possível na medida em que a quantidade pode produzir um salto de qualidade, conforme uma conhecida lei da dialética. Mas deixar para o acaso não é a postura correta. Para Tushman e O’Reilly III (1998; p. 75), as 
organizações necessitam tanto das inovações incrementais, quanto das radicais que produzem descontinuidade. Esses autores criaram a expressão organizações ambidestras para denominar as que conseguem vantagens competitivas operando simultaneamente no curto prazo enfatizando a eficiência e, no longo, as inovações de maior vulto e que envolvem maiores riscos (TUSHMAN; O’REILLY III, 2004; pg 2-3). Um tipo de inovação não existe sem a outra, as inovações portadoras de novidades radicais desencadeiam miríades de ajustes, correções e mudanças de pequena monta que são percebidas após a sua posta em marcha e à medida que sua adoção permite ampliar o conhecimento sobre ela em termos operacionais e mercadológicos. Não considerar as inovações incrementais como componentes importantes das estratégias de inovações é uma espécie de miopia.

Os sistemas de sugestão estudados favorecem a manutenção de um meio interno inovador voltado para a eficiência operacional de curto prazo e receptivo às mudanças de maior vulto, conduzindo ao que Bôer e Gertsen (2003; p 806-7) denominam de inovações contínuas, entendidas como a habilidade de combinar a efetividade operacional com a flexibilidade estratégica para apoiar as inovações com maior grau de novidade e risco. Ou seja, a habilidade para aperfeiçoar o que existe para fazer melhor e com menor custo e desenvolver novos produtos, mercados e sistemas de gestão. Em ambiente altamente competitivo, um sistema de sugestão bem gerido, seja participativo ou remunerado, conforme as características observadas nos casos estudados e na teoria revisitada, pode contribuir para esse duplo objetivo. Os sistemas de sugestões estudados têm o mérito de incentivar o empreendedorismo dos funcionários e com isso estimular o ambiente interno para as mudanças. A propósito, esse é dos objetivos expressos de um dos sistemas estudados, como mencionado. Dessa forma, os sistemas de sugestões podem ser propulsores de um processo para construir esse ambiente complexo que permite que a organização consiga um ritmo de produção sustentável de inovações.

\begin{abstract}
Generating ideas is an essential activity of innovation process. Amongst the ideas sources one can find the systems designed to encourage and capture ideas from employees. This paper presents a bibliographical review on the subject and the results of a study in three Brazilian organizations recognized as innovative that have suggestions systems that meet the expectations for which they were created, according to its managers. This study focused attention on the systems management, its suitability to the company's global management and the results attained. It has brought new considerations on this theme, enabling new theoretical approaches and the proposition of a new classification more appropriate to its new assignments, such as to increase communication between management and employees, valuing the intangible aspects of the work environment and sustaining an internal innovative milieu favorable to all kind of improvements and radical innovations.
\end{abstract}

Key Words: ideas, invention, innovation, innovation management, quality, suggestion systems.

\title{
Referências
}

BELL, M; PAVITT, K. Technological accumulation and industrial growth: contrast between developed and developing countries. In: Industrial and Corporate Change, Vol. 2, No 2, Oxford Univ. Press, 1993. 
BÖER, H; GERTSEN, F. From continuous improvement to continuous innovation: a (retro)(per)spective. International Journal of Technology Management, v. 26, n. 8, p: 805-27, 2003.

cross ref

BÖHMERWALD, P. Gerenciando o sistema de sugestões. Belo Horizonte: Fundação Cristiano Ottoni, 1996.

BONACHE, J. The international transfer of an idea suggestion system: against radical relativism in international human resource management. International Studies of Management and Organization, v.29, n. 4, P: 24-44, winter, 2000.

CLARK, K. B.; WHEELWRIGHT, S. C. Managing new product and process development: text and cases. New York, The Free Press, 1993, p. 2.93.

DEWEY, J. Logic: the theory of inquiry. New York, Holt, Rinerhart e Winston, 1.938.

EISENHARTD, K.M. Building theories from case study research. Academy of Management Review, v.14, n.4, p:532-550, 1989.

cross ref

FREEMAN, C.; SOETE, L. The economics of industrial innovation ( $3^{\text {a }}$ ed.). Londres, Wellington House, 1.997.

FORD, H. Minha vida e minha obra. São Paulo, Editora Monteiro Lobato, 1925.

GODFREY, A. B. Criativity, innovation and quality. Juran Institute, Inc. Series of satellite broadcast presentation, Fev. 2003.

GUNDLING, E. The 3M way to innovation. NY, Kodanska America, 2000. 247 p, pg. 23.

JAPAN HUMAN RELATIONS ASSOCIATION (JHRA). Kaizen Teian 1: developing systems for contínuos improvemente through employee suggestions. Portland: Productivity Press, 1992.

JAPAN HUMAN RELATIONS ASSOCIATION (JHRA). O livro das idéias: o moderno sistema japonês de melhorias e o envolvimento total dos funcionários. Porto Alegre, Artes Médicas, 1997.

JAMES, P. Total quality management: an introduction. New Jersey, Prentice Hall, 1996.

ROGERS, E. M.; Diffusion of Innovations, The Free Press; NY, 1995; $4^{\text {th }}$ ed.

ROTHWELL, R. Successful industrial innovation: critical factors for the 1.990s. R\&D Management. 22 (3): pg. 221239, jul. 1992.

SCHURING, R; LUIJTEN, H. Reinventing suggestion systems for continuous improvement. International. Journal of Technology Management. Vol. 22, n.4, p: 359-372, 2001.

cross ${ }^{\text {ref }}$

STEVENS, G A.; BURLEY, J. 3,000 raw ideas = 1 commercial success! Research. Technology Management. May./jun., p: 16-27, 1997. 
TUSHMAN, M; O’REILLY III, C.A. The ambidextrous organization. Harvard Business Review, Abril, 2004.

TUSHMAN, M; O’REILLY III, C.A. Winning through innovation. N.J.,Prentice-Hall, 1998.

WEG S/A. Relatório anual de 2005. Jaraguá do Sul, WEG S/A, 2.005.

WEG S/A. Círculo de controle de qualidade: o que se deve saber. Jaraguá Sul, WEG, 2.002.

WEG S/A. Preparação para membros e líderes de CCQ. Jaraguá do Sul, WEG, s/d.

YASUDA, Y. 40 years, 20 million ideas: the Toyota suggestion system. Portland: Productivity Press, 1991.

YIN, R. K. Estudo de caso: planejamento e métodos. Porto Alegre, Bookman, 2001.

\section{Dados dos autores:}

\section{Nome completo: José Carlos Barbieri}

Filiação institucional: Escola de Administração de Empresas de São Paulo / Fundação Getulio Vargas - FGV/EAESP

Departamento: Administração da Produção e Operações - POI

Função ou cargo ocupado: Professor

Endereço completo para correspondência (bairro, cidade, estado, país e CEP):

Rua Itapeva, $474,8^{\circ}$ andar

01332-000 São Paulo - Brasil

Telefones para contato: $11-37997780$

e-mail: jose.barbieri@fgv.br

\section{Nome completo: Antonio Carlos Teixeira Álvares}

Filiação institucional: Escola de Administração de Empresas de São Paulo / Fundação Getulio Vargas - FGV/EAESP e Brasilata S/A Embalagens Metálicas

Departamento: Administração da Produção e Operações - POI

Função ou cargo ocupado: Professor na FGV/EAESP e Diretor Superintendente da Brasilata S/A Embalagens Metálicas

Endereço completo para correspondência (bairro, cidade, estado, país e CEP):

Rua Itapeva, 474, $8^{\circ}$ andar

01332-000 São Paulo - Brasil

Telefones para contato: $11-36118122$

e-mail: Teixeira@brasilata.com.br

Nome completo: Jorge Emanuel Reis Cajazeira 
Filiação institucional: Suzano Celulose e Papel SA

Departamento: Diretor de competitividade da Suzano Papel e Celulose

Endereço completo para correspondência (bairro, cidade, estado, país e CEP):

Rua Bandeira Paulista, 555 apt 1604

04532-011 São Paulo - Brasil

Telefones para contato: $11-35039171$

e-mail: cajazeira@.suzano.com.br

Recebido para publicação em: 28/05/2009

Aceito para publicação em: 03/09/2009 